\title{
A 3D VIRTUAL LEARNING ENVIRONMENT FOR TEACHING CHEMISTRY IN HIGH SCHOOL
}

\author{
SHUDAYFAT, E[man]; MOLDOVEANU, F[lorica] \& MOLDOVEANU, A[lin] D[ragos] B[ogdan]
}

\begin{abstract}
The rapid developments in the field of online threedimensional $(3 D)$ virtual worlds have considerable impact on education activities. Therefore, the $3 D$ designers and teachers start to consider the interaction between design and usability of $3 D$ virtual learning spaces as essential tool for educational systems. For the purpose of our research, a virtual learning space was created as a chemistry class using EON software tools. The paper describes the experiments conducted by this learning space and our conclusions in terms of design and usability.
\end{abstract}

Keywords: $3 D$ learning spaces, $3 D$ virtual environments, virtual world, interaction, immersion

\section{INTRODUCTION}

Our present era is characterized by the so-called information revolution, which motivated the governments to recognize its importance and its implications on the development of social, economic, cultural and political.

During a Computer Based Training (CBT) Systems seminar in Los Angeles, in October 1999[1] an unfamiliar concept was used for the first time which was 'Online learning'. This concept and 'virtual learning' were used later to qualify and represent new methods to learn and teach using new technologies, through the Internet or by intranet, extranet, so as to make the process of learning more independent of time and place. Virtual Learning opens up new horizons for the learners that were not available before. It is a promising solution to achieve the students' future needs without overlooking the benefits of the traditional way of teaching.

The researchers prefer to use the term 'e-learning' rather than the term 'virtual learning', because this type of education is similar to the usual education, but it depends on electronic media. Therefore it is "real" not "virtual", as Dobbs and Philip say about the term 'virtual learning': "The e-learner is educated for real, just in an electronic environment" [5].

For a long time, simulation has been used in the learning activities, facilitating accurate representations of real objects, turning learners into interactive participants [12]. After the beneficial role of computer-based simulations has been proved in facilitating learning, it was a good chance to merge the computer-based simulations and virtual environments to create online virtual environments in which the students can access, interact and explore. The final product will be an opportunity for active learning [14].

Virtual reality (VR) environments allow users to interact with objects and environments that they may not be otherwise able to interact with. Virtual Environments are considered to be perfect environments for testing on phenomena that may be too costly or too critical in physical reality. The online three-dimensional (3D) virtual worlds enable users to interact and explore in 3D spaces. Such worlds are typically based upon interactive visualization of $3 \mathrm{D}$ models; text, audio, chat tools are available within the $3 \mathrm{D}$ space and each user is represented as an individual avatar with the ability to react and interact with other avatars [9].

Using the virtual reality technology in the educational process has many advantages such as:

- It enables the learner to explore places and things that are difficult to access.

- It enables the learner to explore the real things without sacrificing the standards of size and time.

The concept of "atom" is fundamental in the chemistry lessons; its understanding is the base for almost every other topic. Using online three-dimensional (3D) environments in the education process makes chemistry concepts more comprehensible to students. Teachers who are skilled at improvisation will be more successful in revealing chemistry information to the students in their classes.

A virtual space can be a perfect environment for creating an interactive multi-user class room, in which learners are able to compare different forms of teaching methods and they have the ability to choose the one they prefer.

Today Virtual Reality environments utilize real-time $3 \mathrm{D}$ graphics that allow simulating complex or dangerous experiments, providing users with realistic but safe experiences. [2][7][13].

\section{RELATED WORKS}

$>$ A study done by Payne [10] aims to explore the views of 1205 second year students of secondary schools, in the state of Wisconsin-Madison of America, about the importance of using virtual laboratories in online learning. The study has shown 
that $53 \%$ of the sample rejected learning in this way, while $47 \%$ responded with acceptance.

$>$ The objective of Shih study [11] is to strengthen the role of virtual laboratories in the educational process, by taking the views of the 1898 high school students from public schools in the state of Utah, U.S. It became clear from the results that $73 \%$ support this trend, and they believe that virtual laboratories are a new step toward distance learning to solve a large part of the suffering in some schools related to laboratory schedules or cost of raw materials.

$>$ The study of Carl [3] analyzed the views of 578 sciences teachers and 2012 students from secondary schools, Ohio, on the use of virtual laboratories in elearning. It became clear from the results that both teachers and students support the new experience, but they are not comfortable with their results, especially as they may not achieve the immediate objectives of the educational process.

$>$ Harry's study [6] compares distance education and traditional education in the faculties of community service mandates of Florida and Arizona. The selected sample was composed of 120 students, distributed into three groups, the control group and two experimental groups. The results show that $61 \%$ of the two experimental groups prefer to have distance learning.

$>$ The study of Crosson [4] was conducted on two groups, a control group and an experimental one. He studied the use of the Internet in the educational process, as an optional model, for the high and middle school education. The results indicate that $83 \%$ of the experimental group prefer homework via the Internet, which is a sign of attention given to education over the internet.

From the mentioned researches we can conclude that using virtual laboratories in e-learning and in educational institutions, would improve the quality of education, if some obstacles could be overcome.

\section{OUR PROJECT}

The aim of our project is to create a friendly, collaborative and innovative virtual environment in the field of Chemistry, a fundamental discipline that accounts for life at the molecular level.

The major challenge that confronts Chemistry teaching is how to teach and explain the main concepts using innovative methods and how to make the chemistry lesson more attractive for the students. Instructors may improve the lectures by merging traditional boards and audio with visual tools, that makes chemistry more alive to the students, as our future students are mostly dependent on visual learning due to the image-centric visual world in which they are raised in.
The 3D perception can also improve the understanding of a chemistry lesson (e.g. the 3D molecular forms of atoms). A 3D virtual environment for teaching chemistry adds more advantages to a traditional e-learning: young people like computer games; computer games have always been successful at capturing peoples' imagination; the most popular of them use immersive 3D environment where gamers take on the role of a character.

Our 3D virtual classroom offers some advantages over traditional teaching and learning methods and tools:

- Provides 3D representations of the objects for each lesson of the course.

- 3D Avatars are used to represent teacher and students

- Both the specific 3D objects and the avatars are mixed in a 3D environment, which leads to user immersion into to subject of the lesson.

- Provides a high scale communication channel such as, instant messaging, voice over IP systems similar to a face-to-face conversation. Giving students the ability to collaborate, discuss and chat about events and artifacts within the virtual world. Although the students will appreciate if they can develop relationships with other students. Such an environment can allow students to leave messages for teachers and other students using documents, links to web sites or videos. It can also serve as a meeting place for live discussions instead of threaded text in the forums or a place for students to work on a project together.

- Our virtual classroom provides and supports the teacher and students with a collection of resources such as: electronic documents, forums, videos, PowerPoint presentations, and links to Web sites.

Those environments are simulations where instead of being an outside viewer the student is part of the simulation, allowing them to explore, discover, and create goals of their own within the simulation. We believe that a virtual environment with a high degree of interactivity is substantially better than one without interactivity.

The first experiment that we have implemented in our virtual environment is a lesson about the periodic table.

\subsection{Our Approach}

Have you ever wondered what your students would say about your class if they could hide behind an avatar in this class? Or, if they can choose the appropriate time for them to enter the class, a place where students can study more and find out information from different sources of information? What your students would say about a place where they can learn and act free, without embarrassment, which is one of the biggest factors which hinder the study process? A place where students can access many type of learning objects, articles and multimedia educational projects, like in a virtual library. 
Our virtual classroom will offer a combination of different resources, all in a 3D environment: from creatively displayed web links to instructional video clips, learning objects, text based documents, interactive spreadsheets, blogs, wikis and branching stories. We try to create such a wonderful place for students, where learning is fun and motivating.

For the creation of our virtual environment we selected the software package named EON Creator. We found it suitable for our case. Thus, it offers extremely easy-to-use modeling and composition using the 3D editor with direct access to a large database of interactive and optimized 3D content on EON Experience Portal. It is a tool that allows users to build engaging interactive learning simulations for training, education and presentation purposes.

Three-dimensional virtual worlds created with EON offer new opportunities for teaching in immersive and creative spaces.

\subsection{The Chemical Periodic Table lesson}

We created a virtual classroom presenting all the objects that can be found in any normal class (see Fig. 1).

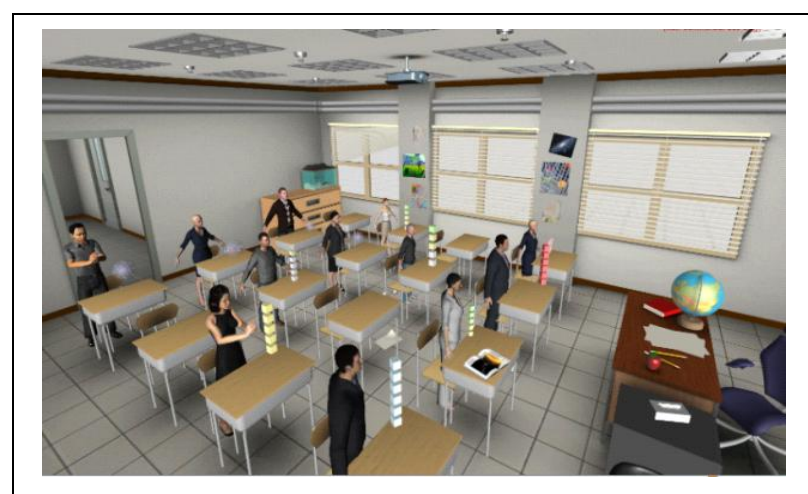

Fig. 1. 3D virtual Environment representing a class room with all possible objects

In our virtual class we have many 3D animated/dynamic objects such as chemical elements atoms and the chemical Periodic table.

For the atoms, we tried to go deep to present all the atom's main components which consist of three main particles located in two regions: the nucleus, containing protons and neutrons, and the second region, which surrounds the nucleus and is named the electron cloud. The cloud holds the third particle which is a negatively charged electron. So, in this virtual space the students will notice and determine the location of the electrons in "P" orbit and "S" orbit and make a comparison between them (see Fig. 2).

In our present work we introduced a new way of representing chemical elements. Unlike the existing way, which is two-dimensional, this new way is a threedimensional one. It arranges the elements in a formative structure of more levels, giving a clear, spatial perception of different relations within the chemical elements.

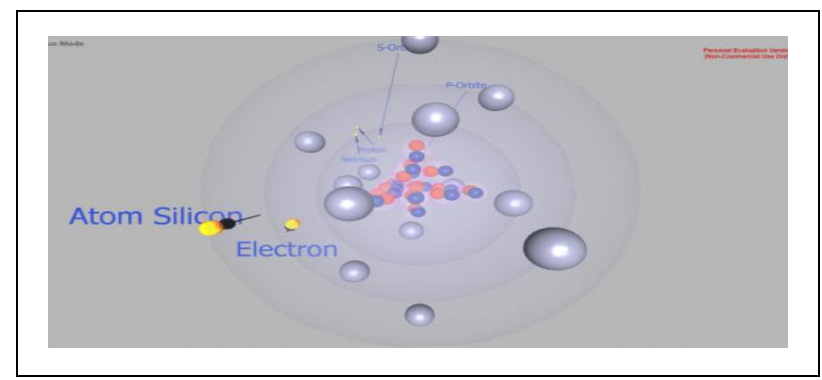

Fig. 2. 3D, dynamic multi-layers representation of a Silicon Atom

In this virtual lesson we represented the chemical periodic table in full format and also we divided it into many groups. We put every group in front of a student avatar. The student can explore the components of each group element, to recognize the chemical specifications for each element. The student can compare atoms based on atomic numbers and recognize the item code number and the electronic number. By clicking on an element of the Interactive Chemical Periodic Table (Fig. 3), the student obtains further detailed information.

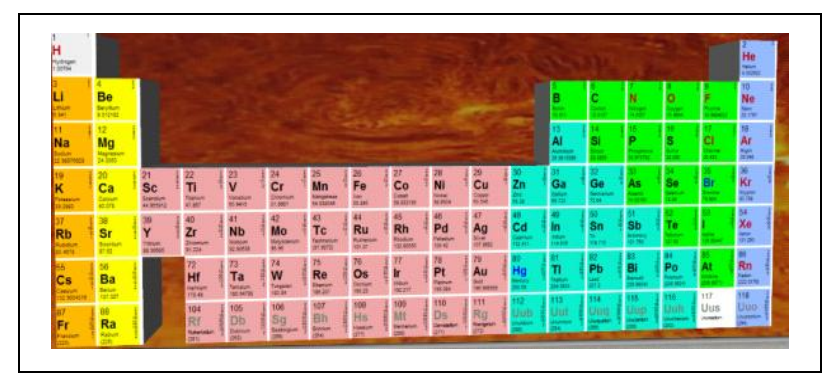

Fig. 3. Interactive Chemical Periodic Table

Our Chemical Periodic Table lesson key features are:

- $\quad$ Easy to use (see Fig. 4)

- Easy to manipulate and run interactions with the objects from the virtual class

- Rich surface for video, PowerPoint, and 3D objects

- Support for stereoscopic 3D presentations.

\begin{tabular}{|c|c|c|}
\hline 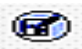 & Annotation & $\Rightarrow$ \\
\hline You & Youtube & $\Rightarrow$ \\
\hline (8) & Wikipedia & 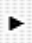 \\
\hline 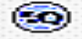 & Quikiki & 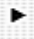 \\
\hline 致 & Hyperlink & 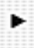 \\
\hline 通 & Presentation & $\triangleright$ \\
\hline (क्व) & Video & 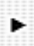 \\
\hline (CB) & Audio & 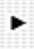 \\
\hline \$9 & Animation & $\triangleright$ \\
\hline E & Transparency & 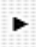 \\
\hline (6) & Rotate & 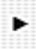 \\
\hline (3) & Exploded Views & 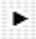 \\
\hline
\end{tabular}

Fig. 4. Interactive Authoring Configuration Tool supported by EON Creator

After the teacher set all or some of the authoring options for each object, the students can check those at run time, to explore more information about the specific object. The Interactive Runtime Tool (Fig. 5) appears for 
each object so the student can navigate all the available options (including PowerPoint, Video, 3D animation, Quiz...)

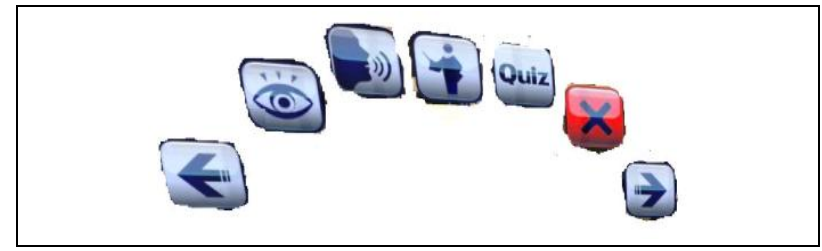

Fig. 5: Interactive Runtime Tool

For more dynamic and more attractive environments, there are many animations for avatars. We used these options to make our 3D virtual class more fun and interesting (see Fig. 6).

Clap
Point
walk
Walketack
Wave
Idle

Fig. 6: Avatar's Options Status supported by EON run time

Our chemical lesson has a VR interface that provides rich representations in colors, textures and behaviors, and allows for real-time navigation within the $3 \mathrm{D}$ virtual space. This enables students to engage and interact with visual graphics, images and 3D shapes in a virtual space, at different levels of representations. And also it supports online, interactive 3D meeting services that allow students and teachers collaborate in a more effective way, using the power of interactive 3D and multi-modal communication.

\subsection{Using the lesson}

The students need to download special client software to run and participate in our virtual class. The download site (no need to register) www.eoncoliseum.com offers support for students and teachers with a ready to use virtual meeting environment, with VOIP service, one to one and one to many. The software and hardware minimal requirements to use the virtual class are:

- Microsoft .Net Framework 3.5 and later installed

- Windows XP/ Vista/ Windows 7 (32-bit and 64-bit)

- Intel CPU $1 \mathrm{GHz}$ CPU with 2GB of RAM

- Participants wishing to connect to audio using VoIP will need an internet of at least $384 \mathrm{kbps}$, a microphone and speakers.

By using the tool which comes with EON application, called "Coliseum 2.0", the students and teachers have the ability to communicate virtually anywhere, anytime. Coliseum 2.0 is online meeting software that packs the non-immersive part of $3 \mathrm{D}$ virtual environments without the hassle of building one as in conventional tools. The student do not need an EON Coliseum account to attend an online meeting, he can participate just as a guest or attendee at totally no cost for him. Performance may vary according to network traffic conditions and the attendees' hardware capabilities.

Our virtual lesson is designed for small to medium group multi-user environments (up to 30 users/students). Before continuing with lesson the student need to know what we mean by the word "Avatar ". Because direct experience acts as a strong catalyst for learning, providing a learner with an avatar, a physical embodiment of the learner in the 3D world appears promising from an educational perspective. In addition to the direct pedagogical benefits, life-like avatars offer significant motivation and immersion.

After the proven success of online animated pedagogical agents [8], we need to make use of that success to create avatars that are visually compelling by exploiting the power of animation.

After all the students receive a "Meeting ID" by email /sms or any available communication channels they can run EON Coliseum 2.0 on their PC's to participate in the class. The main screen will appear on the desktop and then the student must enter the "Meeting ID "exactly the same as he received from his/her teacher. The student chooses a Nick Name, and any Avatar from the sliding list. After that, he/she can join the virtual class.

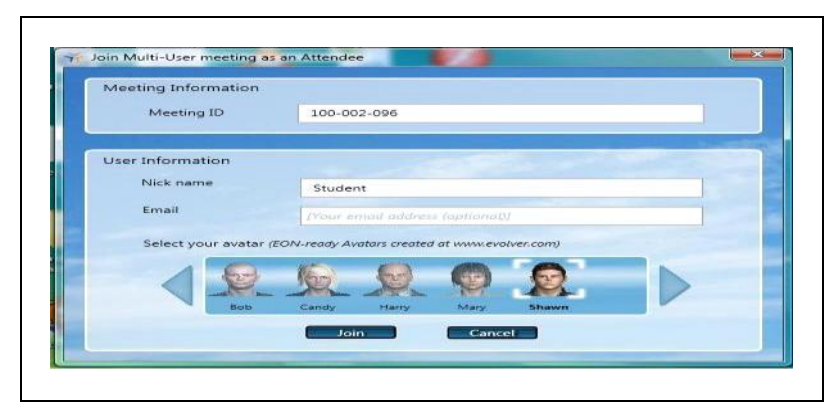

Fig. 7. Multi-user meeting interface for the students as an attendee for our virtual class after the teacher provides the students with the "Meeting ID",

When a student join our chemical virtual classroom he/she will directly be in the virtual space and appear like the avatar which he/she selected in the join screen, with his nick name as a caption (see Fig. 8). The student can select any navigation method to go throw all the objects but first he/she must set up his/her audio option (speakers, microphone). In such an environment all the users will see each other's avatars in the same virtual space.

The right side of our virtual space has three sub screens: the configuration sub screen, "Attendee list" and "Chat". The configuration enables the user to conFig. his PC audio or he can just mute the sound. In addition, there is an extra option for the teacher to control the presentation so she/he can change between students or teachers to have the power of presenting and participate 


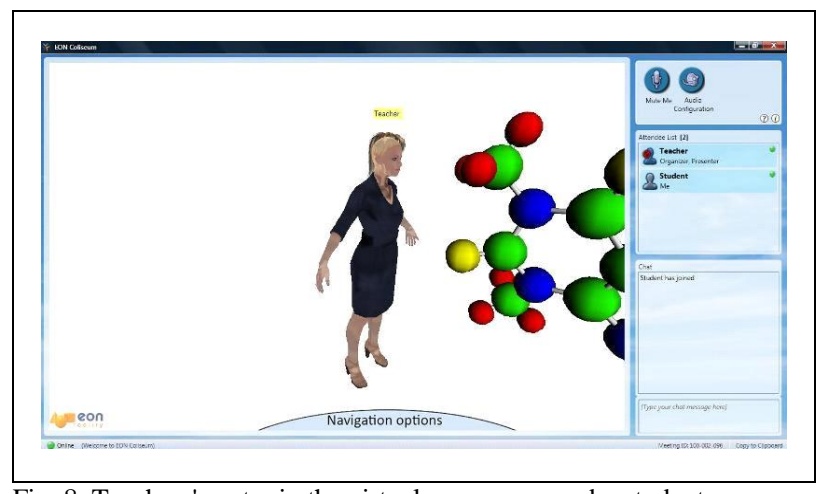

Fig. 8. Teachers' avatar in the virtual space, as seen by students

in the main activities, to create dynamic one-to-many communication environments. The second sub screen, "Attendee List", shows all participant users (teacher /students). The "Chat" sub screen is a sharing board for all users, in which they can chat.

The bottom part of our virtual space contains the "Navigation options". The user can select one of three different ways to navigate through our virtual space: walk (the default navigation option), orbit (rotation on an orbit) and fly. (See Fig. 9).

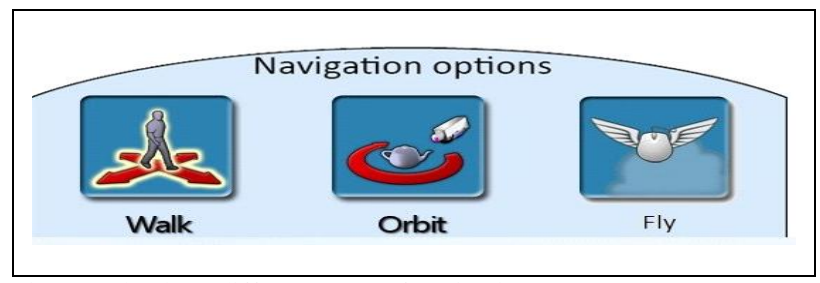

Fig. 10. The three different ways of navigations.

In our virtual classroom, the students can travel through a 3D space, navigating through all the 3D objects, such as atoms and the periodic chemical table. Also they can view and explore simulations for many types of atoms. In an atom simulation, the students can go deep inside the atom, exploring how electrons orbit around the nucleus.

$3 \mathrm{D}$ representations proved to be a powerful tool to visualize and describe complex abstractions in a highly attractive way (see Fig. 10). By clicking on a 3D object the student can obtain information, choosing between many options: texts, sound, still pictures, video, graphics, animation, and hyper links.

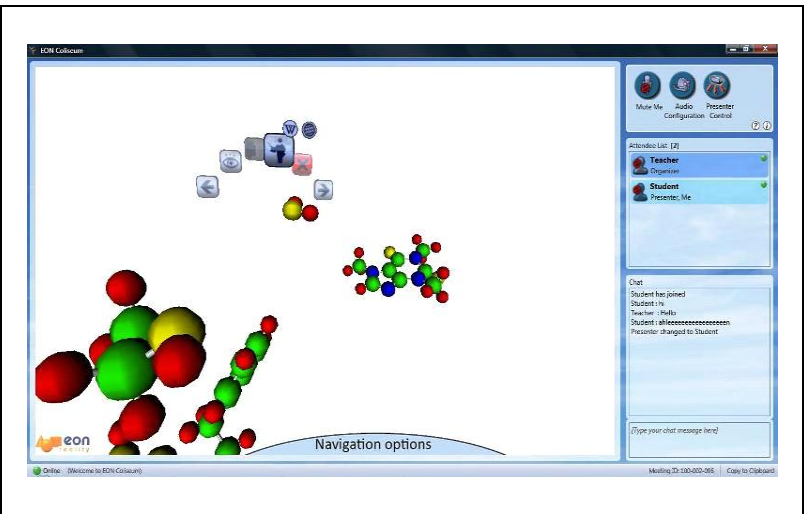

Fig. 10. Options and tools to explore our 3D objects

\section{EXPERIMENTS AND RESULTS}

We have made a first experiment with our chemical virtual environment, trying to analyze the pedagogical, educational, psychological and other aspects of using the virtual space versus the traditional method of teaching.

We used two distinct groups of tenth grade students for an experimental course. For the first group we used the traditional way of teaching. For the second group we tried to teach and explain the same subject using our virtual lesson. After the completion of teaching both groups we conducted a simple test for comparing the results between the two student groups. We observed the difference between the two teaching methods, the traditional and using the virtual 3D environment.

We found that the students from the second group not only get most of the lesson goals but they start to interchange information using the provided communication means. Also, they appreciate this new teaching way (virtual) as being more time flexible, because the student can participate in the lesson at any time as he wants, depending on his free time. They like the idea of using visual elements in education through attractive $3 \mathrm{D}$ objects.

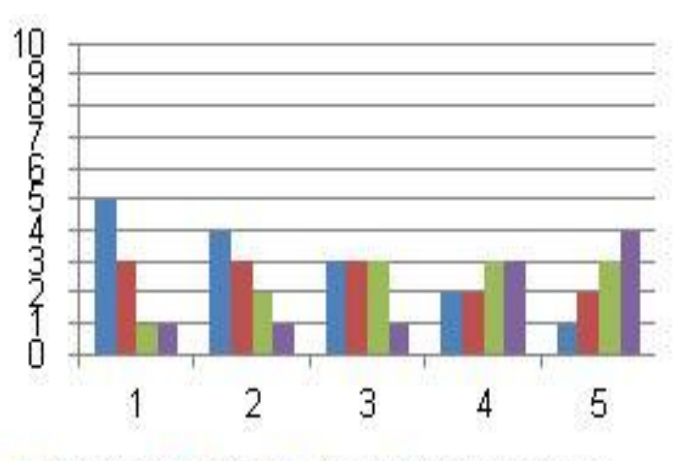

Walking Orbit $\mathrm{Fly}$ Explore Objects

Fig. 11. Feedback on navigation:

Level of Difficulty: 1 = Very Easy, 5= Very Difficult

We made an analysis of the ease of navigation in the virtual space. As can be seen in Fig. 11, feedback on navigation was mixed. Those with experience in 3D computer games found navigation easy while novice users needed time to master the controls. In particular, some of them found it difficult to navigate through objects in the virtual classroom.

We asked the students what they liked most in our virtual lesson:

- Many of the students mentioned they enjoyed activities within virtual class such as being able to move and fly and explore objects in the world ("flying without wings", "you get to go anywhere", "explore and interact all the objects").

- Many others commented positively about the experience of being immersed in a virtual world 
("experiencing a new place without going far", "being in it, and not seeing it just on a screen").

We asked what the students liked least in our virtual class:

- Some indicated the screen resolution on laptops

- Others indicated the difficulties in moving around in the $3 \mathrm{D}$ space.

All participants used the communication facilities. Although test users found them easy to use, some of them experienced difficulty with the audio communication. In particular, some users could hear an echo. This can be caused if speakers are too close to the microphone; clearer instructions on this could reduce this problem. Text-chat proved most popular for collaboration; however this may be largely due to the problems experienced with audio communication.

\section{CONCLUSIONS AND FUTURE WORK}

Our preliminary conclusion from this study is that virtual world can be compelling and creative tool for a better and more advanced educational environment

We agree that teaching of sciences in general and chemistry in particular comes with both risks and complexity. Using a 3D virtual word to overcome the mentioned problems, as our lesson is, provides more potential benefits for student engagement such as the ability to interact with $3 \mathrm{D}$ objects in a virtual environment. We noticed that the interaction in a virtual world increases student engagement in an online class and also students' sense of community with the class. The students are more likely to engage in discussions in a virtual world than they would be in a face-to-face class. The most important benefit of using virtual world is to provide more learning options than the normal face-toface classes such as using discussion boards, instant messaging, or email. Finally, Virtual world presents many interesting opportunities for instructors who are interested in exploring new educational tools and resources in teaching.

From our experience with the creation of the virtual chemistry class, we concluded that the $3 \mathrm{D}$ graphics is a powerful tool for visualizing and understanding complex and abstract information.

Immersion is a recent aspect which has to be better explored and evaluated.

In the traditional chemistry lab there are always risks and dangers. In our next work we will create a 3D virtual laboratory for chemical experiments, using all the available technology and implementing better teaching methods.

\section{REFERENCES}

[1] American Association of Collegiate Registrars and Admissions Officers (AACRAO) (1997). Virtual Learning Environments

[2] Barab, S. A., Hay, K. E., Squire, K., Barnett, M., Schmidt, R., Karrigan, K., et al. (2000). Virtual Solar System Project: Learning through a technology-rich, inquiry-based, participatory learning environment. Journal of Science Education and Technology, 9(1), 7-25

[3] Carl, J. (2006): Telecourse Tactics: Issues in the Dosing and Distance, Educational Tech, Bloomington ,IN, V (83.1)(54)

[4] Crosson, S. (2006): Online Course Design Using the Teac/Learn/ Assess Model, Website http://www.teched.org/2006 .(83-91)

[5] Dubois J and Will Phillip (1997). The virtual learner: Real learner in a virtual environment. Paper presented at Virtual learning environment conference. Denver,USA

[6] Harry, G. (2006) Supplementing classroom instruction with webbased Technologies Pacific University Conference CA, Feb. 21.(213).

[7] Kwon, O. N., Kim, S. H., \& Kim, Y. (2002). Enhancing spatial visualization through Virtual Reality on the web: Software design and impact analysis. Journal of Computers in Mathematics and Science Teaching, 21(1), 17-31

[8] Lester, J.C., Converse, S.E., Kahler, S.E., Barlow, S.T., Stone, B.A., and Bhogal, R (1997). The Persona Effect: Affective Impact of Animated Pedagogical Agents. In Proceedings of CHI '97 359366

[9] Michele D. Dickey (2005) [Three-dimensional virtual worlds and distance learning: two case studies of Active Worlds as a medium for distance education. Published by Blackwell Publishing, 960 Garsington Road, Oxford, USA

[10] Payne, R. (2005): Classroom: For the Next Century, Computer \& Internet Communication, Cresskill, NJ: Hampton Press.(82).

[11] Shih, Y. (2005): Learning Through Internet Courses , www.Nces.ed.gov. USA. (129)

[12] Shuell, T. J. Cognitive Psychology and Conceptual Change (1987): Implications for Teaching Science. Science Education, 71(2), 239-250

[13] Song, K.-S., Han, B., \& Lee, W. Y. (2000, November). A virtual reality application for middle school geometry class. Paper presented at the International Conference on Computers in Education, Taipei, Taiwan

[14] Vullo, R. P. (1991) The Design and Evaluation of a ComputerBased Learning Environment for Secondary Students Incorporating Hypermedia and Simulation. Ph.D. Thesis, State University of New York at Buffalo, Buffalo, NY 